\title{
Conceptual Framework for the Risk Assessment of Hydrological Disasters: A Case from Urumqi, China
}

\author{
Xingwei $\mathrm{Li}^{1, *}$ and Hongyu Long ${ }^{1}$ \\ ${ }^{1}$ School of Management, Jiangsu University, Zhenjiang, Jiangsu, 212013, China \\ ${ }^{2}$ School of Civil Engineering and Geomatics, Southwest Petroleum University, Chengdu, Sichuan, 610500, China
}

\begin{abstract}
Hydrological disasters have become one of the most serious problems facing regional green development. In order to develop a method suitable for comprehensive assessment of urban hydrological disasters, this paper takes Urumqi, China as the research object, and proposes a conceptual framework. Urumqi is an urban area in the northwest of China, and it is often devastated by hydrological disasters. In combination with urban geographic data and the mathematical calculation model of Urumqi, China, the urban hydrological disasters analysis model of Urumqi is established by using the spatial analysis technology of the Geographic Information System according to the risk index of hydrological disaster. Considering the various related factors, like the hazard risk, vulnerability and exposure of disaster, and disaster environment, the risk assessment framework of hydrological disasters in Urumqi is finally designed. In addition, the framework provides a reference for relevant government agencies to develop disaster prevention and mitigation policies.
\end{abstract}

\section{INTRODUCTION}

Humans' living environments face many risks of natural hazards. As one of the natural hazards affecting urban ecology, hydrological disasters restrict the ecological, economic, and social benefits of cities.

Hydrological disasters, also known as hydrological hazards, including drought disasters, snowmelt flood disasters, storm floods, glacial lake floods, hail disasters, frost disasters, snow disasters, and debris flow disasters caused by floods, result in economic losses, casualties, and environmental deterioration caused by extreme hydrological events due to climate change [1-3]. According to the National Bureau of Statistics of China [4], the pollution -disasters dominated by droughts, floods, hail, frost, snow, and debris flows in 2017 affected 184, $762 \mathrm{~km} 2$ in China, accounting for $1.92 \%$ of China's land area.

Against the background of global warming, the frequency and scale of hydrological disasters are increasing rapidly, which has aroused the attention of the international community, and a series of disaster prevention and mitigation plans have been formulated and implemented. However, the core content of hydrological disaster risk management is hydrological disaster risk assessment, which is an important basis for formulating disaster prevention and mitigation policies and emergency plans. The main characteristics of hydrological disaster risk are that they are widespread, result in a large loss, and have a great influence. As these characteristics are closely related to the living environment of people, hydrological disasters have been one of the hotspots for researchers at home and abroad in recent years, and have become one of the most serious problems faced by green development, restricting the development of a green economy and green cities $[5,6]$. However, existing related researches mainly focus on a single type of disaster risk assessment research. There are limitations in the comprehensive assessment of hydrological disaster risk. How to comprehensively assess the risk of hydrological disasters in an urban area? In order to develop a method suitable for comprehensive assessment of urban hydrological disasters, this paper takes Urumqi, China as the research object, and proposes a conceptual framework. Therefore, the innovation of this research is to propose a conceptual framework suitable for comprehensive assessment of urban hydrological disasters.

As the capital of the Xinjiang Uygur Autonomous Region and the core area of the Silk Road Economic Belt, Urumqi belongs to a semi-arid continental climate in the temperate zone. The geographic coordinates of the city are $86^{\circ} 37^{\prime} 33^{\prime \prime}-88^{\circ} 58^{\prime} 24^{\prime \prime} \mathrm{E}, 42^{\circ} 45^{\prime} 32^{\prime \prime}-44^{\circ} 08^{\prime} 00^{\prime \prime} \mathrm{N}$, and the city extends along the rivers in a zonal pattern. Research shows that the main hydrological disasters in Urumqi are caused by floods, snow, and droughts [3].

The purpose of this study is to propose a framework to support the risk assessment of hydrological disasters in Urumqi. This framework mainly uses GIS technology to comprehensively evaluate the risk of hydrological disasters in Urumqi and reveals the distribution of the risk of hydrological disasters in Urumqi. Based on the above, a distribution map of hydrological disasters in

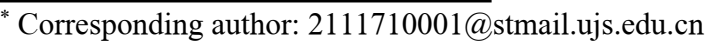


Urumqi is obtained. Finally, the risk distribution law of hydrological disasters is analyzed by GIS software.

Much of the research on hydrological disasters risk assessment has a particular focus, and this backgroundrich study often lacks a framework that limits the ability to link lessons learned to different environments. Framework research helps to reveal how the background of the research results and constraints affects the applicability of this information [7]. In general, framework research is used in the initial stages of a series of studies aimed at building a conceptual framework for subsequent in-depth studies and revealing the methods and potential areas that will be used in subsequent research [8]. In recent decades, there have been a few cities in China affected by drought, flood, hail, frost, snow, and other major hydrological disasters [9]. Located in the East Asian monsoon region, China has become one of the countries in the world with frequent hydrological disasters due to its geographical location, landform, and climate characteristics [10].

The Geographic Information System (GIS) is a kind of spatial analysis technology that originated from geography, and is widely used in risk assessment and other research fields [11]. A large number of scholars have used GIS technology to study the risk of hydrological disasters [12,13], and have obtained rich results. According to the related research of hydrological disasters in Urumqi, scholars have studied these events from the perspectives of the classification of disasters, the division of temporal and spatial distribution, the classification of small watersheds of mountain torrents, statistics and probability analysis based on historical disasters, and the vulnerability assessment of water resources systems [14]. The study found that the main types of natural hazard in Urumqi include earthquakes, mudslides, floods, droughts, windstorms, cold waves, fog disasters, dry hot winds, heavy rains, frosts, heavy snow, and hail. According to the frequency of flood occurrence, using the Tyson polygon method to divide the small watershed in Urumqi, the first to third flood prevention and control areas were divided [15]. During an El Nino year, Urumqi has less precipitation, a lower wind speed, and a higher annual average temperature, and is prone to a warm winter and drought. During a year of La Nina events, Urumqi tends to have more precipitation and a higher wind speed, and is prone to floods in the spring or summer [16]. In recent years, strong frost events have occurred from time to time in Urumqi's agricultural area, which is not conducive to agricultural production [17].

In summary, although some achievements have been made in the study of the risk of hydrological disasters in Urumqi, the researchers have mainly focused on a certain perspective of a certain type of hydrological disaster. However, research on the comprehensive evaluation of drought, flood, hail, freezing, and snow disasters from the perspective of disaster-causing bodies, disaster-bearing bodies, and disaster environments is rare. The assessment of urban hydrological disasters risk can play a very important role in strengthening early urban hydrological disaster warnings, and is an important scientific basis of urban hydrological disaster risk management and decision-making. Therefore, measures can be taken to avoid the risk of urban hydrological disaster to a certain extent. This paper takes Urumqi urban hydrological disasters as the research object, and carries out a comprehensive risk assessment of Urumqi urban hydrological disasters in the context of climate change from the three aspects of hazard, disaster vulnerability, and pregnancy environment. Through an in-depth study of this research framework, the characteristics and evolution trend of the spatial and temporal distribution of regional hydrological disasters can be clarified, the method and index system applicable to the risk assessment of urban hydrological disasters in arid areas are discussed, and the risk and vulnerability risk assessment of urban hydrological disasters in arid areas is carried out. The framework enriches the theory of natural hazards; the framework provides new ideas for future hydrological disaster risk assessment studies; the framework provides a reference for relevant government departments to develop disaster prevention and mitigation policies. Therefore, this paper has theoretical contributions and reference value for hydrological disasters risk assessment research in other countries and regions of the world.

\section{MATERIALS AND METHODS}

The research method used in this paper is literature analysis. First, through systematic analysis of the research on hydrological disasters, the three evaluation dimensions are identified as disaster-causing factors, disaster-bearing bodies and disaster environments $[18,19]$. Then, this paper develops a conceptual framework for the risk assessment of hydrological disasters in Urumqi, China, based on the application of hydrological disasters, their evaluation theories and methods, and GIS in hydrological disaster risk assessment. 


\section{RESULTS AND DISCUSSION}

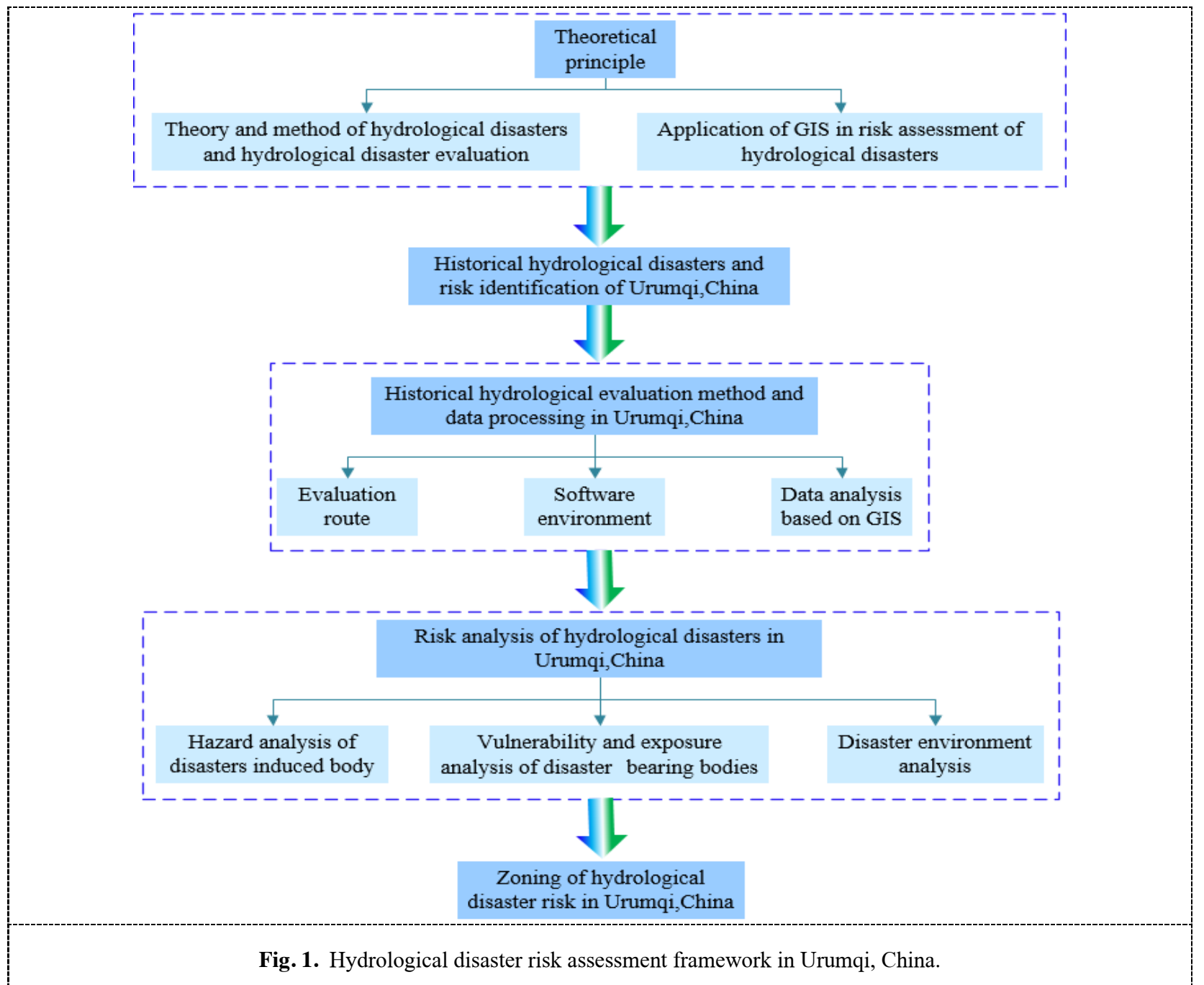

Through participating in practical projects and field research; actively contacting local hydrological and water resources bureaus, meteorological bureaus and other departments to obtain data; and linking theory with practice, we found problems and shortcomings in the study. Following this identification, we summarized them. This paper summarizes and verifies the theoretical risk assessment technology combined with practice, creating opportunities for presenting society with the research results of the risk assessment of hydrological disasters in Urumqi.

This research is based on the application of hydrological disasters, their evaluation theories and methods, and GIS in hydrological disasters risk assessment. First, the paper carries out risk identification based on historical hydrological disasters in Urumqi. Second, the evaluation route and software environment are established, and spatial data analysis is carried out by means of GIS technology. In the hydrological disasters risk analysis section of Urumqi, the analysis of the hazard, the vulnerability and exposure analysis of the bearer, and the analysis of the environment of the pregnant disaster are carried out. Finally, the comprehensive superimposed image data are used to create a hydrological disaster risk zoning map of Urumqi.
Figure 1 shows the risk assessment framework for hydrological disasters in Urumqi.

\subsection{Risk analysis and prediction of hydrological disasters}

\subsubsection{Determination of the risk assessment method and the constitution of the risk system.}

Based on the research results from home and abroad, a mathematical method for the constitution and evaluation of the hydrological disasters risk system in Urumqi is established. The mathematical method of hydrological disaster risk assessment refers to the mathematical expression of risk, exposure, and vulnerability, and the mathematical method of synthesizing or superimposing the three to represent the magnitude of the risk. At the same time, it is necessary to determine the mathematical method of index standardization and weight division because of the different index units. 


\subsubsection{Analysis of the factors influencing the constituent elements of the risk system.}

This process includes the following:

The analysis of risk factors is a systematic analysis of the risk characteristics of hydrological disasters in Urumqi, such as the occurrence times, historical disasters, topography, water system, historical temperature, precipitation characteristics, slope, and elevation of regional historical hydrological disasters.

- The analysis of exposure factors is an in-depth analysis of the characteristics of the factors that affect the exposure of disaster-bearing bodies from the aspects of the population and economy of the region (the number and value of disaster-bearing bodies exposed to disasters).

- Vulnerability impacts factor analysis, which analyzes the impact factor (human disaster awareness, regional emergency rescue ability, regional disaster prevention and resilience, hospital rescue ability, etc.) of the vulnerability of humancentered socio-economic systems.

- Index system construction.

Based on the analysis results on factors influencing the elements of the hydrological disaster risk system, and according to the principles of science, pertinence, rationality, reliability, feasibility, availability of data, and combination of qualitative and quantitative analysis, the evaluation index system of hydrological disaster risk is constructed. According to the method of index weight division, the target layer, criterion layer, and measure layer of the risk, exposure, and vulnerability index are determined, respectively.

\subsubsection{Data collection and preprocessing.}

The index data are selected and extracted from the local chronicles, statistical yearbooks, the Chinese climate disaster canon, Landsat TM images, NOAA, and other remote sensing images of Urumqi. Then, according to the pre-determined method of index, the original indicator data is preprocessed by data standardization.

\subsubsection{Risk analysis and prediction.}

The risk of hydrological disasters, hazard-bearing bodies' exposure, and the magnitude of vulnerability have been respectively analyzed.

The present situation of urban hydrological disasters and the common methods of risk assessment are summarized, and the constitution and characteristics of the hydrological disaster system and hydrological disasters risk system are systematically sorted. By fully considering the uniqueness of urban hydrological disasters in arid areas, as well as by synthesizing the impact of the disaster factors, disaster environment, and disaster-bearing bodies on disaster risk, this paper discusses and establishes the assessment method and index system of hydrological disasters risk suitable for arid areas. Following this, a method for the risk assessment of urban hydrological disasters is proposed.

\subsubsection{Constructing an assessment model of urban hydrological disaster risks.}

According to the risk analysis and evaluation results of hydrological disasters, comprehensive assessment of the risk of hydrological disasters is carried out by using the established index system of risk assessment of hydrological disasters. This project uses the following calculation method:

$R=H \times V$

In the above equation, the risk of hydrological disaster is $R ; H$ is the risk degree of hydrological disaster, indicating the intensity and possibility of disasters; and $V$ is the vulnerability of the disaster-bearing body, which indicates the loss degree of the disaster-bearing body in the event of a disaster.

Because the study area is faced with a common threat from droughts, floods, geological disasters, snow disasters, and hail, the risk degree of hydrological disasters $\mathrm{H}$ is calculated by the weighted comprehensive index method.

$$
H=\sum_{i=1}^{n} w_{i} \times h_{i}
$$

In the above equation, $H$ is the comprehensive risk degree of regional hydrological disasters; $h i$ is the risk degree of a particular type of hydrological disaster; $w i$ is the weight, indicating the degree of impact on a particular type of disaster on a regional scale; $n$ denotes the total number of influencing factors; and $i$ represents the various influencing factors, indicating drought, geological disasters, floods, snowstorms, and disasters.

The vulnerability of disaster-bearing bodies is affected by natural conditions and the level of social and economic development. The index can be expressed as follows:

$V=\sum_{i=1}^{n} w_{i} \times v_{i}$

Here, $V$ represents the vulnerability degree of the disaster-bearing body, $v i$ is the vulnerability degree of regional hydrological disaster factors, wi is a weight that indicates the influence degree of this factor in the region, $\mathrm{n}$ denotes the total number of influencing factors, and $i$ denotes each factor.

By evaluating the model, based on the data on historical hydrologic disasters in Urumqi, the temporal and spatial variation characteristics and evolution trend of hydrological disasters are analyzed. By analyzing the risk factors, exposure and vulnerability of hydrological disasters, and comprehensive risk identification in different periods (mainly 1949 to 2015) and different regions in Urumqi, as well as by extracting the types of hydrological disasters which have the most significant influence on Urumqi, the causes of hydrological disasters in Urumqi are analyzed. 


\subsection{Discussion}

GIS technology is widely used in hydrological disasters risk assessment research [20-22]. Through GIS spatial analysis, a risk distribution map of hydrological disasters in Urumqi has been constructed. This has mainly been produced from the following links: design problems, data selection, selecting analysis methods, processing data, and viewing results. For example, according to the risk index of hydrological disasters, using the spatial analysis technology of GIS, combined with the urban geographic database and mathematical calculation model of Urumqi, the urban hydrological disaster analysis model of Urumqi has been established. The model is the basis of urban hydrological disaster calculation and simulation. According to the distribution of urban hydrological disasters, the characteristic data of urban hydrological disasters can be simulated and predicted by this model.

The risk factors of hydrological disasters in Urumqi, the exposure of Urumqi to disaster-bearing bodies, and the vulnerability analysis of hydrological disasterbearing bodies of Urumqi were evaluated by GIS Technology. This led to the construction of a risk distribution map of hydrological disasters in Urumqi city from 1949 to 2015.

Referring to a large amount of literature related to the risk assessment of urban hydrological disasters at home and abroad, this paper has conducted an in-depth study on the theory and technical system of risk assessment of urban hydrological disasters, grasped the relevant principles and methodologies, and provided basic literature data for Urumqi hydrological disasters risk assessment research. By conducting the case study on the risk assessment of urban hydrological disasters carried out at home and abroad, such as the risk assessment of flood and water logging disasters in a certain city, the risk assessment of snow and hail disasters in a certain city, etc., this paper has analyzed the application of the principle of risk assessment and its application to risk assessment measures in typical cases to assist the hydrological disaster risk assessment study in Urumqi. By comparing the technical system and concept gap of domestic and foreign hydrological disaster risk assessments and analyzing the relative dynamics at home and abroad, this paper has presented breakthrough points for research on hydrological disaster risk assessment in Urumqi. Additionally, it has put forward risk assessment measures and methods of urban hydrological disasters by employing a case study.

\section{CONCLUSIONS AND RECOMMENDATIONS}

\subsection{Conclusions}

In this paper, a risk assessment framework of hydrological disasters in Urumqi is constructed. The main research contributions are as follows:

(1) The present situation of urban hydrological disasters and the common methods of risk assessment have been summarized, and the constitution and characteristics of the hydrological disaster system and hydrological disasters risk system have been systematically sorted. By fully considering the uniqueness of urban hydrological disasters in arid areas, as well as by synthesizing the impact of the disaster factors, disaster environments, and disaster-bearing bodies on disaster risk, this paper has discussed and established the assessment method and index system of hydrological disasters risk suitable for arid areas. Following this, a method for the risk assessment of urban hydrological disasters has been proposed;

(2) Based on the data on historical hydrological disasters in Urumqi, the temporal and spatial variation characteristics and evolution trend of hydrological disasters have been analyzed. By analyzing the risk factors, exposure and vulnerability of hydrological disasters, and comprehensive risk identification in different periods (mainly 1949 to 2015) and different regions in Urumqi, as well as by extracting the types of hydrological disasters which have the most significant influence on Urumqi, the causes of hydrological disasters in Urumqi have been analyzed;

(3) The risk factors of hydrological disasters in Urumqi, the exposure to disaster-bearing bodies of Urumqi, and the vulnerability analysis of hydrological disaster-bearing bodies of Urumqi have been evaluated;

(4) A risk distribution map of hydrological disasters in Urumqi city from 1949 to 2015 has been constructed, and the risk assessment measures and methods of urban hydrological disasters have been put forward.

In addition, this study has some limitations. Although this study focuses on the methods and theoretical frameworks involved in the construction of the hydrological disasters risk assessment framework in Urumqi, it does not focus on the quantitative relationships in the framework, which should be the focus of future research.

\subsection{Policy implications}

This paper has important reference value for governments around the world to formulate relevant policies for urban hydrological disaster risks.

First, this study found that disaster risk research is an interdisciplinary study and that the field is of interest to researchers in the fields of geography, meteorology, ecology, management and others. Therefore, it is recommended that governments around the world increase support for disaster risk research and support interdisciplinary perspectives and methods to solve key technical problems in disaster risk research.

Second, this study found that disaster-causing factors, disaster-bearing body and hazard-inducing environment are three important evaluation dimensions of the factors that contribute to urban hydrological disasters. Therefore, governments and countries in the world should formulate targeted disaster prevention and mitigation policies around these three aspects.

Finally, since urban hydrological disaster risks involve the comprehensive risks of multiple natural 
disasters, it is recommended that governments around the world strengthen the comprehensive collaboration of various government departments. In this way, government departments can achieve barrier-free forecasting and governance policies in disaster prevention and mitigation.

\section{Acknowledgements}

This research was funded by Special Funds of the National Social Science Fund of China, grant number 18VSJ038.

\section{References}

1. G. Sun, C. Pan, J. Li, Yang, Y. Spatial distribution of the extreme hydrological events in Xinjiang, north-west of China. Natural Hazards, 67,483-495 (2013)

2. X. Li, J. Du, Long, H. A Comparative Study of Chinese and Foreign Green Development from the Perspective of Mapping Knowledge Domains. Sustainability, 10,4357 (2018)

3. X. Li, J. Du, H. Long, Sun, G. Characteristics and risk analysis of hydrological disaster events from 1949 to 2015 in Urumqi, China. Theoretical and Applied Climatology, 137, 745-754 (2019)

4. National Bureau of Statistics of China. National Data. http://data.stats.gov.cn/easyquery.htm?cn=C01 (accessed on January 12, 2019)

5. X. Li, G. Sun, H. Long, X. Zheng, L. Wang, Wang H. Research Progress of Urban Hydrological Disaster Risk Assessment From 1988 to 2017. Journal of Sichuan University of Science and Engineering (Natural Science Edition), 31,74-82 (2018). (in Chinese)

6. X. Li, J. Du, Long, H. Theoretical framework and formation mechanism of the green development system model in China. Environmental Development, 32, 100465 (2019)

7. L.D. Jenkins, S.J. Dreyer, H.J. Polis, E. Beaver, A.A. Kowalski, H.L. Linder, Wiesebron, L.E. Human dimensions of tidal energy: A review of theories and frameworks. Renewable and Sustainable Energy Reviews, 97,323-337 (2018)

8. E. Tempero, Ralph, P. A framework for defining coupling metrics. Science of Computer Programming, 166, 214-230 (2018)

9. H. Baojuan, W. Yetang, S. Weijun, Xiaoyan, W. The unique "Regional East Gale with Blowing Snow" natural disaster in Jeminay County, Xinjiang Uygur Autonomous Region, China. Natural Hazards, 93,1105-1108 (2018)

10. S. Wu, T. Pan, Yang Q. Risk pattern and Prevention of Major Meteorological and Hydrological disasters in China. Science publishing house, Beijing (2014) (in Chinese)
11. J. Parker, A. Donnellan, M. Glasscoe, G. Fox, J. Wang, M. Pierce, Ma, Y. Advantages to Geoscience and Disaster Response from QuakeSim Implementation of Interferometric Radar Maps in a GIS Database System. Pure and Applied Geophysics, 172, 2295-2304 (2014)

12. X. Li, Z. Sun, G. Sun, W. Zhao, Wang, T. Influence of Hail Disaster on Fruit Trees in Aksu Prefecture. Journal of Agricultural Catastrophology, 6,32-35 (2016) (in Chinese)

13. Z. Sun, X. Li, G. Sun, T. Wang, Zhao, W. Risk assessment of main hydrological disaster of fruit trees in Aksu Prefecture of Xinjiang. Agricultural Science Journal of Yanbian University, 38,242247(2016) (in Chinese)

14. M. Wulamu, Moming A. The city disaster characteristics and disaster reduction countermeasure in Urumqi. Journal of Geological Hazards and Environment Preservation, 12,12-16 (2001) (in Chinese)

15. J. Bing, Dou, X. Study on the Critical Rainfall Distribution and Prevention and Control Regionalization of Mountain Flood Disasters in Urumqi. Research of Soil and Water Conservation, 12,252-255 (2005) (in Chinese)

16. X. Xi, Zhao, J. Study on Climate Change in Urumqi and Relationship with EI Nino/La Nina Events in Recent 49 Years. Arid Zone Research, 29,826-831 (2012) (in Chinese)

17. Y. Zheng, Gong H. Climatic Characteristics of Cold Wave in Urumqi. Desert and Oasis Meteorology, 9,56-61(2015) (in Chinese)

18. Y. Zhang, G. Fan, Y. He, Cao, L. Risk assessment of typhoon disaster for the Yangtze River Delta of China. Geomatics, Natural Hazards and Risk, 8, 1580-1591 (2017)

19. J. Gao, Sang, Y. Identification and estimation of landslide-debris flow disaster risk in primary and middle school campuses in a mountainous area of Southwest China. International Journal of Disaster Risk Reduction, 25, 60-71 (2017)

20. G.C. Ohlmacher, Davis, J.C. Using multiple logistic regression and GIS technology to predict landslide hazard in northeast Kansas, USA. Engineering Geology, 69, 331-343 (2003)

21. B. Bajracharya, A.B. Shrestha, Rajbhandari, L. Glacial Lake Outburst Floods in the Sagarmatha Region. Mountain Research and Development, 27,336-344 (2007)

22. C. Samela, R. Albano, A. Sole, Manfreda, S. A GIS tool for cost-effective delineation of flood-prone areas. Computers, Environment and Urban Systems, 70,43-52 (2018) 